\title{
British Society of Gerodontology Winter Meeting 2019
}

The theme of the sold out Winter Meeting of the British Society of Gerodontology on 4 December at the Royal Society in London was 'Ageing well with good oral health'. The conference was well attended by dentists and dental care professionals (DCPs). President of BSG Mili Doshi set the scene saying: 'we have an ageing population and it is important that maintaining good oral health is on the agenda across health and social care'.

Opening the conference was Health Education England duo Peter Briggs and Tom Clayton speaking about future planning for the demographics of the UK with the increasing age of the population and the need for 'palliative dentistry' for older patients retaining their natural teeth for longer, as well as future planning for our workforce in the 'Advancing Dental Care' project.

Mark Ide, periodontist and current British Society of Periodontology (BSP) president focused on concepts for periodontal care for older adults and the emerging evidence around the two-way relationships between oral and systemic health - including Alzheimer's disease.

Next was the first of the two interactive conference presentations which asked for audience participation. Natalie Bradley, StR in Special Care, spoke about Do Not Attempt Resuscitation Orders and Advanced Decisions and how it may impact dental treatment for older patients. In the audience, only $23 \%$ had any training surrounding DNAR orders or routinely asked their adult patients about DNAR status on their medical histories. Forty-eight percent of the audience were confident in

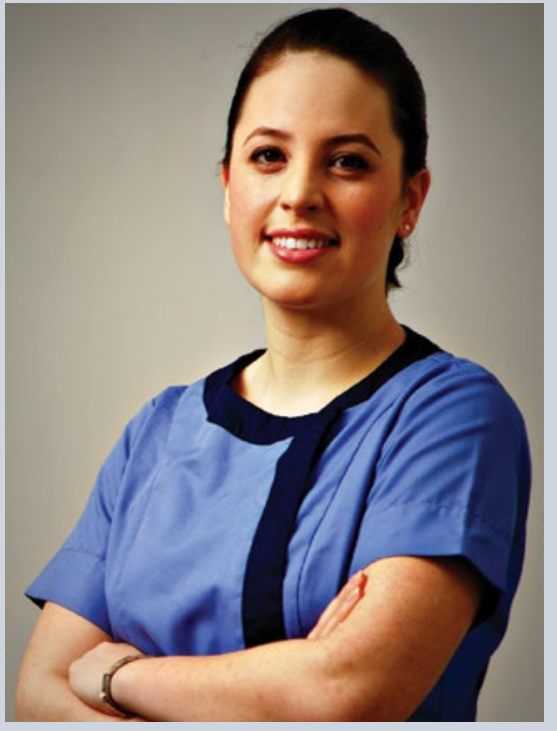

Natalie Bradley

discussing DNAR status with their patients.

Considerations for older people's anaesthesia was discussed in the next presentations with anaesthetist Afolake Bewaji and Clinical Fellow Tara Fernado. They discussed how older people can be more sensitive to certain anaesthetic drugs and have a higher risk of post-operative or emergency delirium which needs to be discussed with the patient and their family.

This was followed by Jane Peterson, a dental hygienist and founder of Knowledge Oral Health Care, who shared her experiences of delivering oral health promotion and prevention in care homes and the challenges she faced.

Before lunch, best-selling author Wendy Mitchell gave an inspiring talk of her experiences of someone who was diagnosed with early onset dementia at the age of 58 and how this has impacted her life. She also shared some really insightful experiences of what dentists should consider when treating patients with dementia. For example, speaking to the patient first instead of automatically speaking to their carer or relative, or considering how patients with dementia may be hypersensitive to certain pitches of sound which could include our dental drill.

After lunch, Panna Shah and Sarah Segelman led another interactive presentation discussing clinical conundrums when treatment planning for older patients. This was followed by Professor Martin Ashley who discussed some of the excellent work he has been leading in Manchester in improving the oral health of older people including working with Mouth Care Matters with inpatients in hospitals.

The final speaker of the day, Graham Manley, finished the day with a highly entertaining talk describing his experiences in special care dentistry across his career, patients with neuro-disability and some the research and development of medical electronics in the rehabilitation of these patients.

Overall the day was highly successful with talks from across health professionals in the holistic management of older patients to ensure that our patients age well and maintain good oral health into old age.

BSG will hold its Spring Meeting at ManDec in Manchester on 12 June with the theme of 'Oral Health at the End of Life'. See the BSG website for further information. https://www.gerodontology. com/courses-and-events/

By Dr Natalie Bradley, Special Care Dentistry Registrar and Dr Mili Doshi, Special Care Dentist

\section{New Year Honours}

MBE: General dental practitioner

Dr Jason Wong of The Maltings Dental

Practice, Grantham, Lincolnshire

becomes an MBE in the New Year

Honours List 2020. The MBE has been

awarded for services to dentistry and

oral health. Dr Wong has interests in oral health promotion and implant dentistry, and is an LDC Secretary and Local Dental Network Chair.

BEM: Retired Manchester dentist Dr Peter Kurer has been awarded BEM for services to Holocaust Education.
DBE: Baroness Floella Benjamin, who has championed children's oral health and said it needs to be on the Government's agenda and that NHS dentistry needs to be properly funded, becomes a Dame Commander of the Order of the British Empire (DBE). 